\title{
POSSIBLE CYTOTOXIC EFFECTS OF SILVER NANOPARTICLES ON THE PAROTID GLANDS OF ALBINO RATS
}

\author{
Rasha Mohamed Taha* and Rania Hanafi Mahmoud Said**
}

\begin{abstract}
Background: Silver has found to have many uses in the medical field due to its unique properties on the nanoscale, therefor the toxicity of nanosilver has become a hot topic and interesting area of research.
\end{abstract}

Aim of the study: The study aimed to explore whether the silver nanoparticles (AgNPS) have a cytotoxic effect on the parotid gland of male albino rats.

Materials and methods: The sample of study consisted of 30 adult male albino rats whose average body weight ranged from 250 to 300 grams and they were divided into two groups: Group 1 was consisted of 10 rats and served as controls, they received $0.5 \mathrm{ml}$ deionized water per os using curved metallic oro-pharyngeal tube for 21 days. Group 2 was consisted of 20 rats, they received $10 \mathrm{mg} / \mathrm{kg}$ b.w/day AgNP solution (in deionized water) with particle sizes ranging from 3 to $20 \mathrm{~nm}$ per os using curved metallic oro-pharyngeal tube (the recommended dose of each rat is $1.5-1.8 \mathrm{mg}$ dissolved in $0.5 \mathrm{ml}$ deionized water) for 21 days. The animals were observed for any body weight changes. The 30 rats were sacrificed after ending the experiment and dissection and separation were applied to their parotid salivary glands which were then fixed in $10 \%$ neutral buffered formalin. Afterwards, they were processed, fixed in paraffin, separated and stained with: 1-Hematoxylin and Eosin for histological evaluation of the parenchymal and stromal elements of the glands to detect any histological changes. 2-Streptavidin-biotin immunohistochemical method for localization of Ki67 for detection of the proliferation of cells.

Results: The study found that the serous acini swelled with abnormal architecture and illdefined outline. In addition, the study could not distinguish the lining cells of the serous acini. The serous acinar cells showed deeply stained, large hyperchromatic nuclei and mitotic cell division of the acinar cells. Focal oncocytic changes of acinar cells were observed. There was a dilation of the excretory ducts with wide lumen and they were vacuolated degenerated thick epithelial lining. As a result of the effect of the AgNPs, the connective tissue septa of the parotid glands widened and resulted in an in increase in the fibrosis with chronic inflammatory cells infiltration. Blood vessels showed dilatation and engorged with RBCs. In the lobes of parotid gland, the focal areas revealed

\footnotetext{
* Lecturer in Oral Biology Department, Faculty of Dentistry, Suez Canal University

** Assistant professor in Oral Pathology Department, Faculty of Dentistry, Suez Canal University
} 
that their secretory elements have been completely degraded, resulting in a large empty vacuole which was surrounded by deep infiltration of chronic inflammatory cells. Immunohistochemical examination revealed intense nuclear and cytoplasmic Ki67 immunoreactivity of acinar cells, ductal cells and endothelial cells lining blood vessels.

Conclusion: Silver nanoparticles causing dramatic changes in the parotid gland. Even though, AgNPs have several therapeutic uses, their toxicity and therapeutic benefits should be weighed before a clinical decision to use them is reached.

KEYWORDS: Nano particles applications, silver nanoparticles toxicity, ki67

\section{INTRODUCTION}

A very important role is played by Silver nanoparticles (AgNPs) in nanoscience and nanotechnology. In addition, they have become highly applied in nanomedicine as they enter cells and interact with their elements. ${ }^{1}$ The AgNPs consist externally of small silver particles whose length ranges from 1 to $100 \mathrm{~nm}$ in one dimension at least. ${ }^{2}$ From the commercial perspective, they are often called colloidal silver or silver nanoparticles. Further, they commonly used today due to their antimicrobial, antifungal and antiviral characteristics ${ }^{3}$. Among the nanomaterials which have the highest value are the AgNPs and that's why they are used widely in a number of biomedical applications such as diagnosis, treatment, drug delivery, medical device coating, and for health care ${ }^{4}$. AgNPs have a broadspectrum antimicrobial, antifungal ${ }^{5}$ and antiviral activity $^{6}$. They showed beneficial effect in killing prokaryotic microorganisms such as Escherichia coli $^{7}$, Pseudomonas aeruginosa ${ }^{8}$ and antibioticresistant bacterial strains ${ }^{9}$. AgNPs may react with water as they are used as coal of water filters in homes and $\mathrm{Ag}^{+}$released followed by oxidation ${ }^{10}$. Oxidation participates in the formation of $\mathrm{Ag}_{2} \mathrm{O}$ on the particles ${ }^{11}$, which are then dissolved in aqueous media ${ }^{12}$. Oxidative dissolution is an important step in $\mathrm{Ag}_{2} \mathrm{~S}$ (sulphides) formation from/ at $\mathrm{AgNPs}^{13}$. AgNPs sulphidation has got a great attention, as the resulting sulphide is insoluble in water, lowering the availability of $\mathrm{Ag}^{+}$and passive impacting their antibacterial ${ }^{14}$ and toxicological effects ${ }^{15}$. Over time, processes such as sulphidation may convert the AgNPs to a less hazardous form $^{16}$, but the long exposure of their core in the environment ${ }^{17}$ and prolonged activity after their intended application may adversely affect many ecosystems ${ }^{18}$. For this reason, AgNPs have been known as a potential environmental hazard ${ }^{19}$.

At the levels of molecular and cellular, the majority of published researches generally revealed the mechanisms of cytotoxic responses induced by AgNPs (an increase in producing reactive oxygen species (ROS), apoptosis, DNA damage, proinflammation, necrosis and autophagy) in vitro experiments $^{20}$. Some studies showed that when AgNPs were used in mice and rats, they resulted in a decrease in the rate of growth of the treated mice and had an effect on the intestinal microvilli and the liver ${ }^{21}$. However, other studies indicated that the AgNPs had no effect on the body weight ${ }^{22}$. The route of exposure, dosage as well as duration were usually considered as important factors which have an effect on the bioavailability, biodistribution and pathophenotypic outcomes of toxicant exposure ${ }^{23}$. Some properties of AgNPs that may affect their degree of toxicity and hence their applications such as their particles size and shape, their chemical composition the crystalline configuration, type of coating on the nanoparticles and the surface charge and biodegradability ${ }^{24}$.

Although AgNPs are potentially toxic, a previous study demonstrated some therapeutic effects of AgNPs in mice model of peritonitis. The mice treated with AgNPs, exhibited reduced accumulation of inflammatory cells and production of inflammatory 
cytokines. Via an upregulated expression of transforming growth factor $\beta 1$ (TGF- $\beta 1$ ), AgNPs were observed to induce the proliferation of skin keratinocyte and the production of vascular endothelial growth factor (VEGF) and Interleukin 10 (IL-10) $)^{25}$. Furthermore, it was reported that AgNPs promoted local formation of new blood vessels (angiogenesis) and therefore, facilitated healing in a mouse model of burn wounds ${ }^{26}$. This study is a trail to assess the cytotoxic effects of AgNPs administration through swallowing by oropharyngeal tube that may occur in the parotid salivary gland of male albino rat.

\section{MATERIAL AND METHODS}

The present study was approved from the Research Ethics Committee, Faculty of Dentistry, Tanta University.

The study carried out on thirty adult male albino rats with an average of 250-300 grams body weight. They were housed in rat cages, labelled with numerical numbers and kept in well ventilated animal house of the Faculty of Dentistry, Suez Canal University, at a temperature of $27-30^{\circ} \mathrm{C}, 12$ hours natural light and 12 hours darkness. The animals were fed with dry rat pellet and allowed drinking water adlibitum. The animals were observed for any body weight changes.

The animals were divided randomly into two groups as follows:

- Group 1 were consisted of 10 rats and served as controls, they received $0.5 \mathrm{ml}$ deionized water per os using curved metallic oro-pharyngeal tube for 21 days.

- Group 2 were consisted of 20 rats, they received $10 \mathrm{mg} / \mathrm{kg}$ b.w/day AgNP solution (in deionized water) with particle sizes ranging from 3 to 20 $\mathrm{nm}$ per os using curved metallic oro-pharyngeal tube (the recommended dose of each rat is 1.5$1.8 \mathrm{mg}$ dissolved in $0.5 \mathrm{ml}$ deionized water) for 21 days $^{27}$

\section{Preparation and characterization of the Silver nanoparticles:}

Rapid green method is used; it was done in the nanotechnology lab in the Faculty of Science, South Valley University.

From the local market, pomegranate fruits were bought and so were the silver nitrate $\left(\mathrm{AgNO}_{3}>\right.$ 99.9\%) and chloroauric acid (> 99.9\%). Then, proper washing using de-ionized water was applied to all glass-wares and pome fruit and they were dried in the oven. As a reduction agent, Pome's Fruit peel extract (FPE) was employed to develop silver nanoparticles.

Fresh fruit peels $(50 \mathrm{~g})$ were properly washed and added in $250 \mathrm{ml}$ ultra-pure water in $500 \mathrm{ml}$ Erlenmeyer flask and boiled for 10-15mins. Then, for filtering the boiled material in order to prepare the aqueous fruit peel extract to be used for metal nanoparticle synthesis, the Whatman filter paper (No. 40) will be employed.

The preparation of aqueous solution (1ml) of silver nitrate chloroauric acid solution was carried out and the solution of $50 \mathrm{ml}$ of the metal $(\mathrm{Ag} / \mathrm{Au})$ ion was diluted with $1.8 \mathrm{ml}$ of FPE in the temperature of room for 5 minutes. Using a lower amount of this FPE and in order to get a significant Surface Plasmon Resonance (SPR) for the metal nanoparticles, the solution required more than 10 minutes.

In order to develop the nanoparticles at different reaction conditions, the spectral analysis was carried out using UV-Vis spectroscopy based on Perkin-Elmer Lamda-45 spectrophotometer and XRD. In addition, to analyze the size and shape of the developed nanoparticles, Transmission Electron Microscope (TEM) JEM-1200EX, JEOL 1010 was employed.

To measure the TEM, the $3 \mu \mathrm{L}$ of the sample solution was fitted on copper grid resulting in a thin film of sample on the grid and then it was left to be dried at the temperature of room for 15 minutes and 
using the cone of a blotting paper, the extra sample was eliminated and kept in grid box.

By using Energy Dispersive X-ray analysis (EDX) with Zeiss Evo 50 instrument, it was determined if there was an elemental silver. $\mathrm{HCl}$ and $\mathrm{NaOH}$ were used to maintain the $\mathrm{pH}$ of the solution.

The solutions which resulted from developing silver nanoparticles will be dried at $800^{\circ} \mathrm{C}$ to measure the distraction of X-ray powder which was acquired by the EMMA diffractometer in the central laboratory at South Valley University.

The 30 rats were sacrificed after ending the experiment and dissection and separation were applied to their parotid salivary glands which were then fixed in $10 \%$ neutral buffered formalin. Afterwards, they were processed, fixed in paraffin, separated and stained with:

1- Hematoxylin and Eosin for histological evaluation of the parenchymal and stromal elements of the glands to detect any histological changes.

2- Streptavidin-biotin immunohistochemical method for localization of Ki67 for detection of proliferation of cells.

Data will be collected, compared and evaluated statistically.

\section{Statistical analysis:}

In order to hold a comparison of the means of immunoreactivity of Ki67 between the control group and AgNPs group, the study used the Paired Student's t-test. In case the value of $p<0.05$, it is considered significant.

\section{RESULTS}

\section{Body weight results:}

The means of weights of rats were calculated and tabulated (Table I.)
TABLE (I) The means of body weights between group I and group II

\begin{tabular}{|l|l|}
\hline Groups & Body weight \\
\hline Control (group I) & $270 \pm 10.3$ \\
\hline Treated group (AgNPs) (group II) & $240 \pm 11.8$ \\
\hline
\end{tabular}

The differences of the means of body weights between the control (group I) and the AgNPs treated group (group II) were calculated using Paired Student's t-test (Table II, Histogram I)

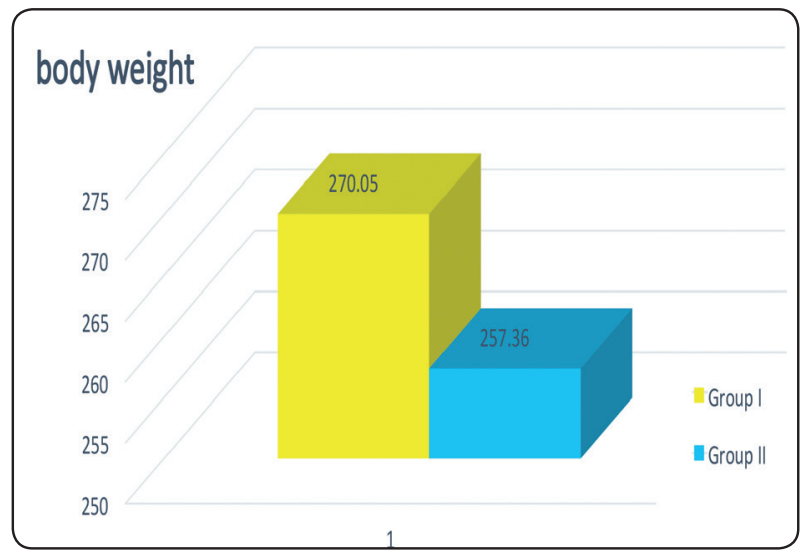

Histogram (I) Showed difference in body weight mean between control group and AgNPs group

TABLE (II) Showed no significant decrease of rats' body weights of group II comparing to control group I

\begin{tabular}{|c|c|c|c|}
\hline \multicolumn{3}{|c|}{$\begin{array}{r}\text { Difference in mean of body weight between Group I and } \\
\text { Group II groups using Paired Student's t-Test }\end{array}$} \\
\hline \multirow{2}{*}{ Group } & M \pm SD & t-Value & p-Value \\
\cline { 2 - 4 } & \multicolumn{3}{|c|}{ Optical Density } \\
\hline Group I & $270.05 \pm 17.91565$ & \multirow{2}{*}{2.26216} & 0.127182000 \\
\hline Group II & $257.36 \pm 16.15037$ & & \\
\hline
\end{tabular}

No Significant difference, $(p>0.005)$.

\section{Nanoparticles characterization}

The size and shape of particles were estimated 


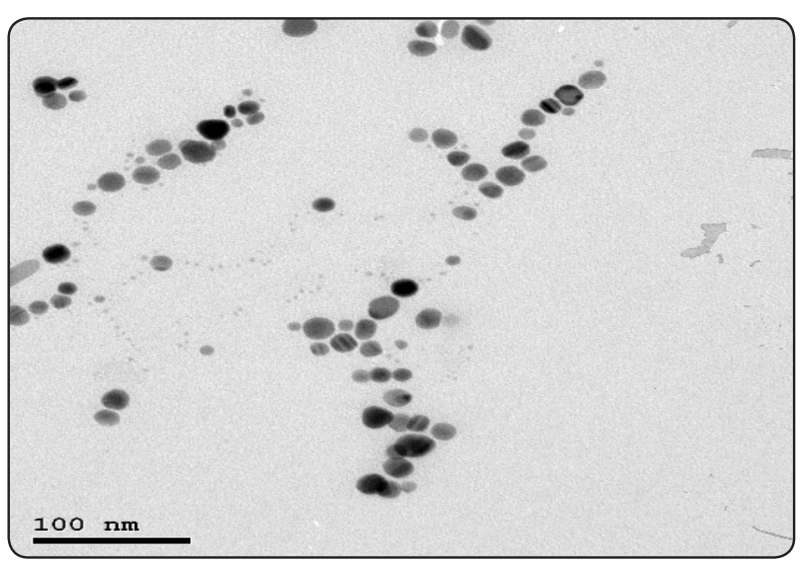

Fig. (1) Representative TEM image of the AgNPs verified spherical morphology and was used to determine primary particle size which ranges from $3-20 \mathrm{~nm}$ and are mostly with spherical shape.

and photographed by EM with the primary particle size ranges from 3-20nm, mostly with spherical shape which was verified through spectral signature identification at 430nm (Fig.1).

\section{Examination with light microscope:}

\section{Group I (Control group)}

After examining the rat parotid glands of control group using the light microscope, it was revealed that the parotid gland texture was normal and histological and consisted of pure serous acinar cells and ductal systems. The shape of serous acini was unified with narrow lumen and basophilic cytoplasm. In addition, the serous acini lined by pyramidal secretory cells with rounded basal basophilic nuclei. The components of the Ductal system were the intercalated, striated, excretory, and main ducts. As the intercalated ducts were very small in size and compressed in between the serous acini and were lined by small cuboidal cells with central rounded nuclei, they were hardly discovered. For the Straited ducts, they were pale, large in number and lined by single layer of columnar cells having centrally placed nuclei. For the inter-lobar ducts (excretory ducts), they were lined by pseudostratiefied columnar epithelium having goblet cells. Finally, the connective tissue septa dividing the gland into lobes and lobules were obvious (Fig.2(A\&B).

\section{Group II (received AgNPs):}

After examining the serous acini, it was evident that they swelled with abnormal architecture and illdefined outline and it was impossible to distinguish the lining cells of the serous acini. Deeply stained and large hyperchromatic nuclei were shown by the serous acinar cells. Further, our results showed mitotic cell division of the acinar cells (Figs. 3). In some focal areas in the gland, oncocytic changes of acinar cells were revealed (Fig.3\&4). The Excretory ducts were reduced with wide lumen having
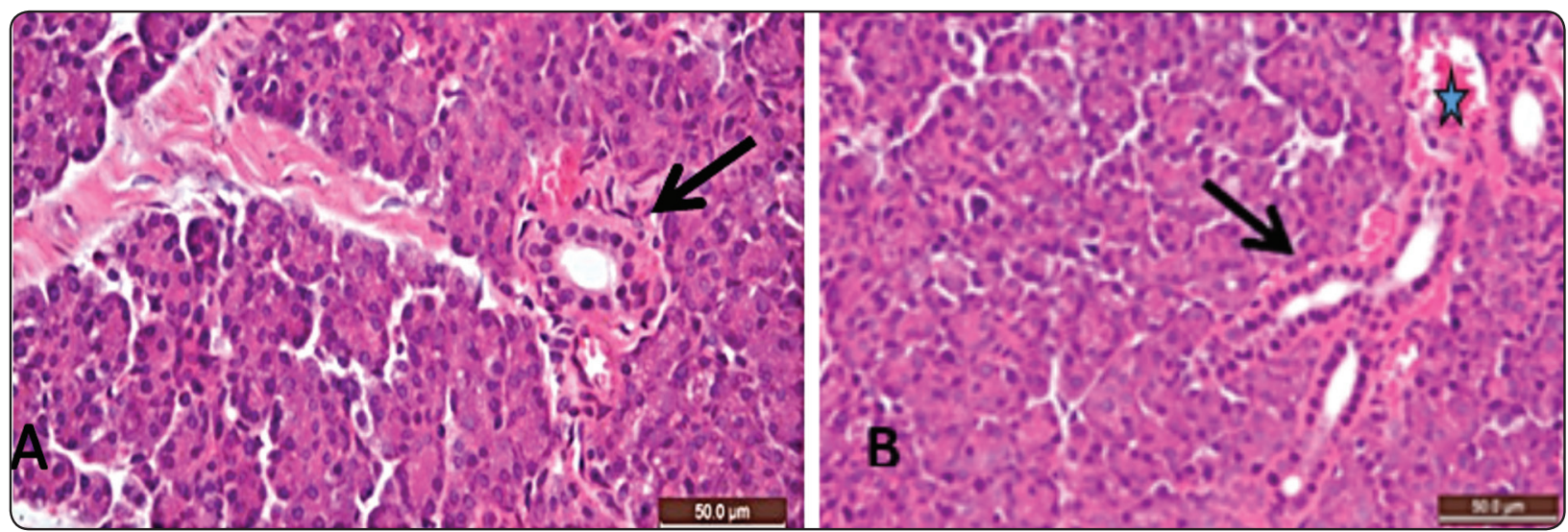

Fig. (2) Photomicrographs of parotid gland from control group showing uniform acinar cells with (A) striated ducts. (Arrow) (B) blood vessel (star) and excretory ducts (Arrow) in connective tissue septa (H\&E Orig.mag.X400). 
vacuolated, degenerated and thick epithelial lining. As a result of the effect of AgNPs, the connective tissue septa of the parotid glands widened and led to an increase in the fibrosis with chronic inflammatory cells infiltration. Moreover, blood vessels were dilated and engorged with RBCs (Figs.4\&5). A complete degeneration of their secretory elements was shown by focal areas in lobes of parotid gland, resulting in large empty vacuoles which were surrounded with deep infiltration of chronic inflammatory cells. In some areas of the serous acini, cytoplasmic vacuolization was uncovered (Fig. 6).

\section{Immunohistochemical examination:}

\section{Immunostaining of Ki67 protein:}

\section{Group I (Control group):}

Control group revealed mild nuclear and cytoplasmic Ki67 immunoreactivity for some acinar cells and ductal cells (Fig.7).

\section{Group II:}

Immunohistochemical examination revealed intense nuclear and cytoplasmic Ki67 immunoreactivity of acinar cells, ductal cells and endothelial cells lining blood vesseles (Figs.8).

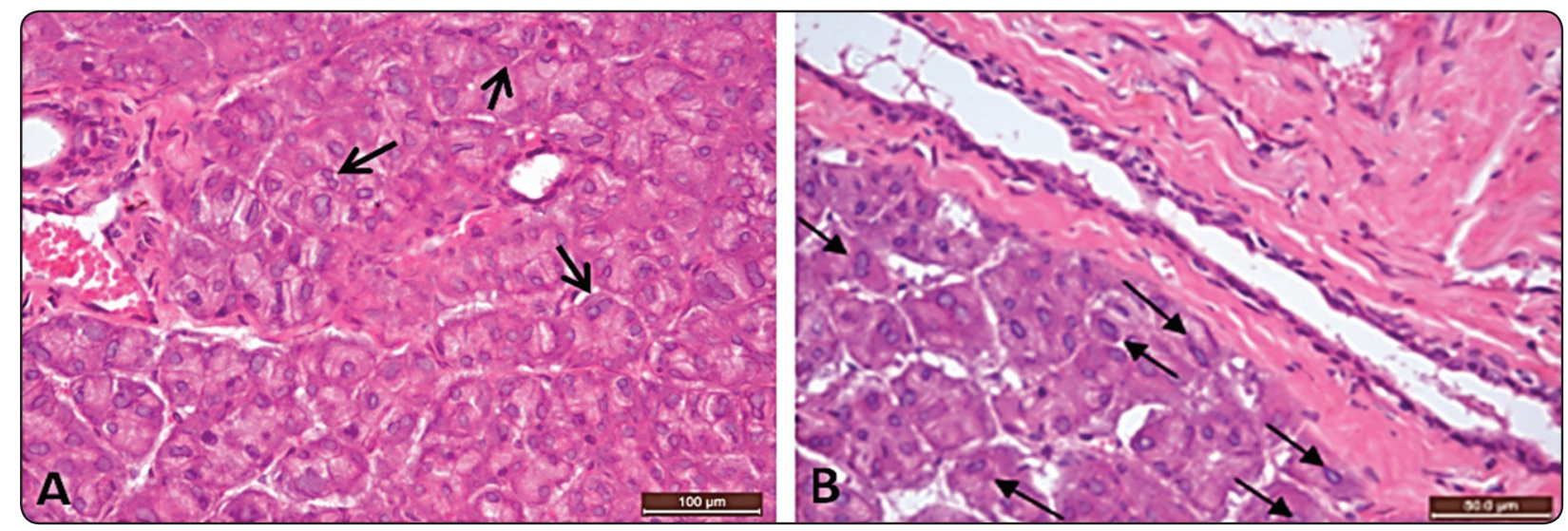

Fig. 3 (A) A Photomicrograph of parotid gland of group II showing hyperchromatism of nuclei of the serous acinar cells, oncocytic changes of secretory elements and increased mitotic figures (Arrows) in connective tissue septa (H\&E Orig.mag.X400). (B) A Photomicrograph of parotid gland of group II showing execratory duct with widening of its lumen and thin, vacuolated epithelial lining, oncocytic changes in the acinar cells (Arrows) (H\&E Orig.mag.X400).
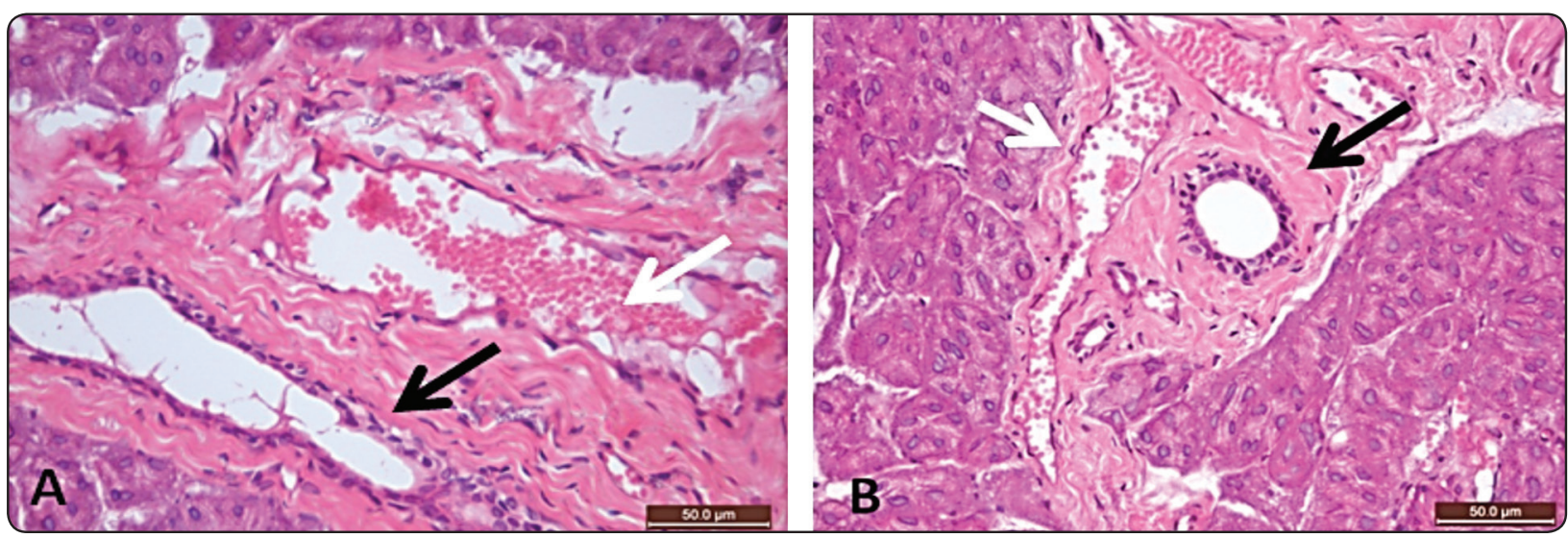

Fig. 4 (A\&B) Photomicrographs of parotid gland of group II showing increase fibrosis surrounding the excretory duct(black arrow), and dilated blood vessels engorged with RBCs (white arrow), (H\&E Orig.mag.X400) 

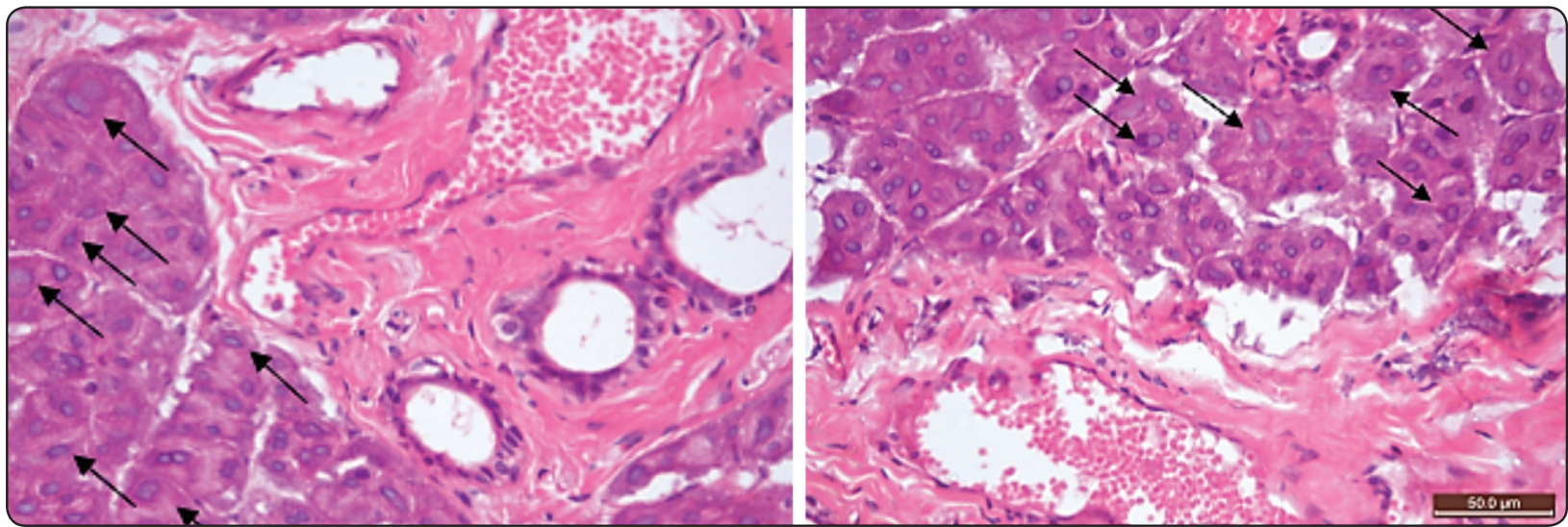

Figs. (5) Photomicrographs of parotid gland of group II showing hyperchromatic nuclei of acinar cells, focal areas of oncocytic changes of acinar cells, fibrosis of connective tissue stroma with inflammatory cell infiltration and blood vessels engorged with RBCs (H\&E Orig.mag. (arrows)X400)

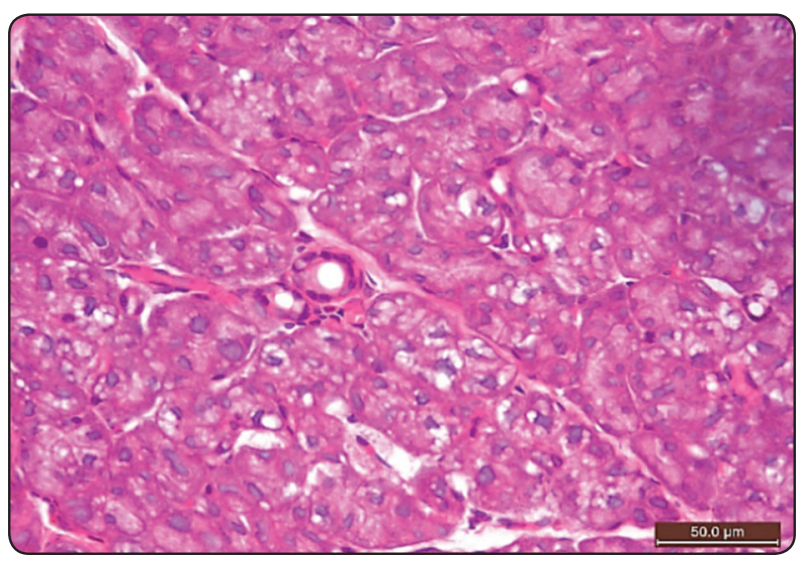

Fig. (6) A photomicrograph of parotid gland of group II showing cytoplasmic vacuolization of acinar cells. Notice hyperchromatic of nuclei of acinar cells. (H\&E Orig.mag.X400).

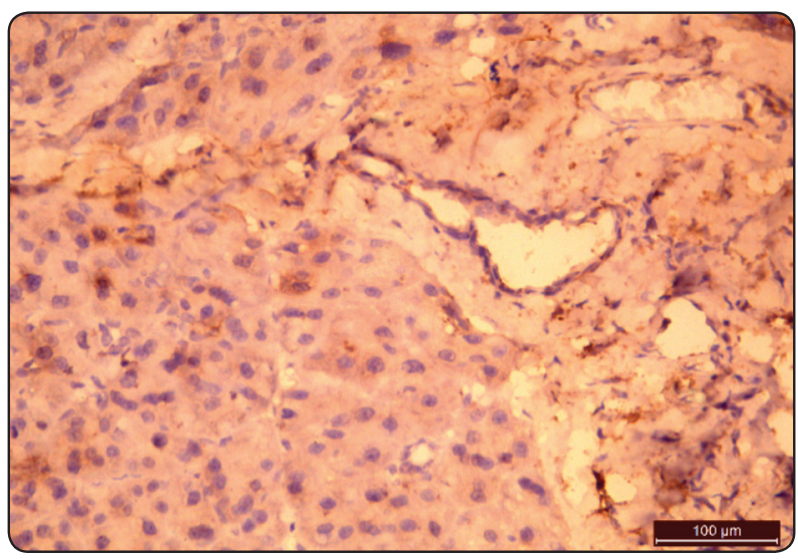

Fig. (7) A photomicrograph of the parotid gland tissue from control group incubated with mouse monoclonal antibody of Ki67 showing mild cytoplasmic Ki 67 immunostaining reactivity of the acinar and ductal cells.(Ki67 mag.X400)

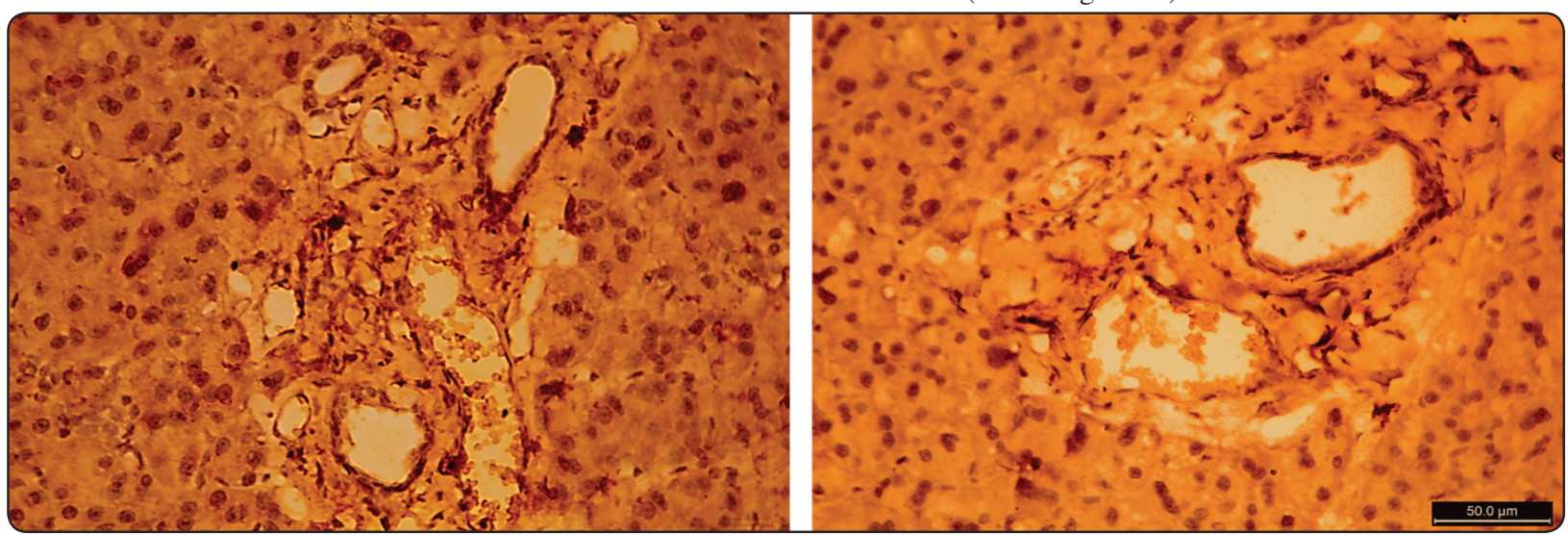

Fig. (8) Photomicrographs of the parotid gland tissue from group II received AgNPs incubated with mouse monoclonal antibody of Ki67 showing strongly cytoplasmic and nuclear Ki 67 immunostaining reactivity of the acinar, ductal and endothelial cells.(Ki67 mag.X400) 


\section{Statistical analysis using Paired Student's t-Test}

Showed a significant marked increase in the mean of optical density of the immunoreactivity of Ki67 protein in group II (AgNPs group) compared with group I (control group) received water vehicle deionized water (Table III). The significant difference in the mean of optical density between the control group (group I) and the group II is represented in a histogram II.

TABLE (III) Showed the significant difference in Ki67 immnuoreactivity between the control group and group II which received AgNPs

\begin{tabular}{|c|c|c|c|}
\hline \multicolumn{3}{|c|}{$\begin{array}{r}\text { Difference in mean of body weight between Group I and } \\
\text { Group II groups using Paired Student's t-Test }\end{array}$} \\
\hline \multirow{2}{*}{ Group } & $\mathrm{M} \pm \mathrm{SD}$ & t-Value & p-Value \\
\cline { 2 - 4 } & \multicolumn{3}{|c|}{ Optical Density } \\
\hline Group I & $48.9902 \pm 4.8546$ & & \\
\hline Group II & $99.4533 \pm 6.2639$ & & \\
\hline
\end{tabular}

No Significant difference, $(p>0.005)$.

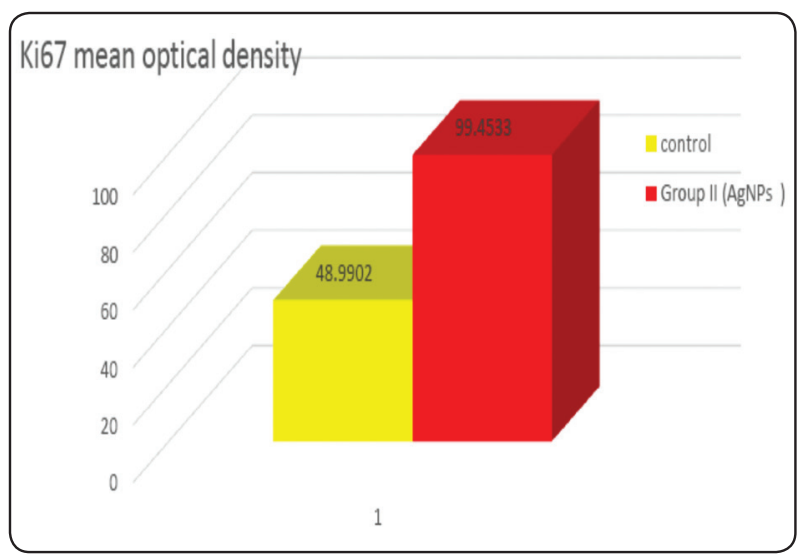

Histogram II: Represents difference in the mean Ki67 optical density between the control group I and group II which received AgNPs.

\section{DISCUSSION}

Silver nanoparticles (AgNPs) remain a controversial inquiry area with respect to their toxicity to biological systems. From results of the present study the mean of body weights did not decrease significantly between the control group and group received silver nanoparticles (AgNPs) 3-20nm. These results are in consistent with the study conducted by Mary et al (2016), as they reported no biological significance difference in body weights between control water vehicle group and AgNPs (10-110nm) received group ${ }^{27}$. On the other hand, Kim et al (2008) found significant decrease in body weights in male rats received oral administration of $60 \mathrm{~nm} \mathrm{AgNPs}^{28}$.

AgNPs targeted the mitochondria as their first choice place to go in the liver cells of experimental rats. In the same study endosomes were found to be filled with AgNPs suggesting that endocytosis was the mechanism of entrance of AgNPs into the targeted cells ${ }^{29}$.

Furchner et al (1968) reported that when AgNPs entered the body about (99.6\% in mice, $98 \%$ in rats, $90 \%$ in dogs and $94 \%$ in monkeys) of the total given amount of AgNPs were excreted from liver bile and went out of body as faecal wastes. That means $0.4 \%$ up to $10 \%$ of silver ions retained in body tissues. Fuschner et al estimated the urinary excretion of AgNPs as (0.001 (mice), 0.001 (rats), 0.019-0.26 (monkeys) and 0.025-0.061 (dogs) ${ }^{30}$. Colloidal AgNPs (particle sizes up to $20 \mathrm{~nm}$ ) were found to be more toxic than the larger particle sizes as they are able to cross the basement membrane and accumulate in body tissues ${ }^{31}$. Liver, spleen, intestine, stomach and heart are the organs that have highest levels of accumulated AgNPs and when they accumulate in skin they cause argyria which appear as bluish grey $^{32}$. When silver ions accumulate in tissues that may cause weight loss, neurotoxicity and enlarged liver and heart. As reported liver enzymes increase and the blood values of interleukins (IL-1, IL-4 and IL-6) become 
elevated. Lui et al (2010), provided an evidence that links between increase AgNPs in cells and elevated reactive oxygen species (ROS) and hence increase in oxidation stress and cytotoxicity. ${ }^{33}$ The effects of interactions between oxidative stress ROS and transforming growth factor $\beta$ (TGF- $\beta$ ) were identified as important factors promoting fibrosis in most, if not all, organs. As the most potent profibrogenic cytokine, TGF- $\beta$ was observed in nearly all fibrotic disease ${ }^{34}$, which explains why this study reported the fibrotic changes in the connective tissue septa and stroma around ducts. In addition, essential roles are played by ROS in initiating and developing vascular dysfunctions which are associated with aging and diseases such as ischemic and chronic heart disease, stroke, hypertension, atherosclerosis, diabetes mellitus and chronic kidney disease ${ }^{35}$. A study by Freed and Gutterman (2013), indicated that through the mitochondrial ROS-dependent and -independent mechanisms, mitochondrial membrane depolarization produces endothelium-derived relaxing factors including $\mathrm{NO}$ which promotes tissue perfusion ${ }^{36}$. These findings come in agreement with results of this study that demonstrated vasodilatation of the blood vessels engorged with RBCs.

Cortese-Krott (2009) demonstrated that AgNPs induce pro-inflammatory cytokines ${ }^{37}$, which result in massive amount of free radicals in cells through increase the expression of NOX/NADPH oxidase family $^{38}$, which may cause DNA damage and cell death and apoptosis ${ }^{39}$. In general, the apoptosis and necrosis is perceived as representing the 2 fundamental forms of cell death but Majno and Joris (1995) showed some logical inconsistencies with this analysis. The Necrosis is precisely defined as "the sum of degradative changes that follow any type of cell death" and the apoptosis is considered to cause cell death with cell shrinkage and nuclear fragmentation. As Majno and Joris have applied the term "oncosis" to the contrasting pattern of cell death with cell swelling, necrosis is inevitably perceived as following the onset of either apoptotic cell death or oncocytic cell death ${ }^{40}$. The previous study gives explanation to our finding of focal areas of oncocytic changes of acinar cells.

Mainly Ki67 immunostaining marker is used as a detector for neoplastic growth of cells and as a proliferative index $(\mathrm{PI})^{41}$. Ki67 protein is usually found in the nuclei of cells that are going on proliferation, and it appears evident in all active cell cycle phase and is absent in cell rest phase $\mathrm{G}_{0}$ (quiescent phase) ${ }^{42}$. Lately, the expression of membranous and cytoplasmic Ki67 was shown in immunohistochemical studies of hyalinising trabecular adenoma of the thyroid gland.

In our results, nuclear, cytoplasmic and membranous Ki67 protein was detected in acinar, ductal and endothelial cells. Detection of Ki67 in cytoplasm and in membranes is unknown, many attempts were directed to explain such results. A study by Leonard et al, (2007) based their explanation on technical artifact or cross-reactivity of KI67. Cross reactivity may be due to changing temperatures during incubation period of $\mathrm{Ag}-\mathrm{Ab}$ reaction ${ }^{43}$. Another study explained the cytoplasmic expression of Ki67 as some immunohistochemical kits contain specific antibody against Ki67 protein (MIB-I) which can detect Ki67 protein in cytoplasm $^{44}$. Faratian et al (2009) investigated the immunoreactivity of Ki67 in invasive breast cancer and detected nuclear and cytoplasmic and membranous staining for Ki67 protein. They explained the membranous staining of Ki67 as abnormal functional forms of $\mathrm{Ki} 67$ which were recognized in membranes ${ }^{45}$.

In addition to its proliferative role, Ki67 has a critical secondary function of repairing damaged DNA. Ciardiello et al (2003), explained that increase expression of Ki67 in cells which had high apoptotic activity and necrosis to antagonize the death of cells and encouraging the DNA to proliferate ${ }^{46}$. The previous studies are in consistent with our results, as explained before, when AgNPs became accumulated in acinar and ductal cells. 


\section{CONCLUSION}

Sliver nanoparticles causing dramatic changes in the parotid gland. Even though, AgNPs have several therapeutic uses, their toxicity and therapeutic benefits should be weighed before a clinical decision to use them is reached.

\section{REFERENCES}

1. CameronS. J. and Willmore W. G. A. Current Overview of the Molecular Effects of nanosilver. Int. J. Mol. Sci. 2018, 19:2030-2122

2. McShan, D. Ray, P.C. and Yu, H. Molecular toxicity mechanism of nanosilver. J. Food Drug Anal. 2014, 22:116-127

3. You C. Han C. Wang X. Zheng Y. Li Q. Hu, X. and Sun $\mathrm{H}$. The progress of silver nanoparticles in the antibacterial mechanism. clinical application and cytotoxicity. Mol. Biol. Rep. 2012; 39:9193-9201.

4. Ge L. Li Q. Wang M. Ouyang J. Li X. and Xing M.M. Nanosilver particles in medical applications: synthesis, performance, and toxicity. Int J Nanomedicine. 2014; 9: 2399-2407.

5. Panáček, A. Antifungal activity of silver nanoparticles against Candida spp. Biomaterials. 2009; 30:6333-6340.

6. Humberto L. H. Garza-Treviño E. N, Ixtepan-Turrent L.and Singh D.K. Silver nanoparticles are broad-spectrum bactericidal and virucidal compounds. J. Nanobiotechnol. 2011; 9: 30-

7. Sondi, I. \& Salopek-Sondi, B. Silver nanoparticles as antimicrobial agent: a case study on E. coli as a model for Gram-negative bacteria. J. Colloid Interface Sci. 2004; 275, 177-182.

8. Poole, K., Krebes, K., McNally, C. \& Neshat, S. Multiple antibiotic resistance in Pseudomonas aeruginosa: evidence for involvement of an efflux operon. J. Bacteriol. 1993; 175:7363-7372.

9. Panáček, A. et al. Silver colloid nanoparticles: synthesis, characterization, and their antibacterial activity. J. Phys. Chem. 2006; B110, 16248-16253.

10. Rosa LR, Rosa RD, Da Veiga MAMS. Colloidal silver and silver nanoparticles bioaccessibility in drinking water filters. J Environ Chem Eng. 2016; 4:3451-3458

11. Lok C. N. Silver nanoparticles: partial oxidation and antibacterial activities. J. Biol. Inorg. Chem. 2007; 12:527-534.
12. Ma, R .Size-controlled dissolution of organic-coated silver nanoparticles. Environ. Sci. Technol. 2012; 46:752-759.

13. Liu, J., Pennell, K. G. and Hurt, R. H. Kinetics and mechanism of nanosilveroxysulfidation. Environ. Sci. Technol. 2011; 45:7345-7353.

14. Reinsch, B. C. Sulfidation of silver nanoparticles decreases Escherichia coli growth inhibition. Environ. Sci. Technol. 2012; 46:6992-7000.

15. Devi, G. P. Sulfidation of silver nanoparticles reduces its toxicity in zebrafish. Aquat. Toxicol. 2015; 158:149-156.

16. Levard, C., Hotze, E. M., Lowry, G. V. and Brown, G. E. Environmental transformations of silver nanoparticles: impact on stability and toxicity. Environ. Sci. Technol. 2012; 46:6900-6914.

17. Sharma, V. K., Siskova, K. M., Zboril, R. and GardeaTorresdey, J. L. Organic-coated silver nanoparticles in biological and environmental conditions: fate, stability and toxicity. Adv. Colloid Interface Sci. 2014; 204: 15-34.

18. Justo-Hanani, R. and Dayan, T. The role of the state in regulatory policy for nanomaterials risk: analyzing the expansion of state-centric rulemaking in EU and US chemicals policies. Res. Policy 2014; 43:169-178.

19. Fabrega, J., Luoma, S. N., Tyler, C. R., Galloway, T. S. \& Lead, J. R. Silver nanoparticles: behaviour and effects in the aquatic environment. Environ. Int. 2011; 37:517-531.

20. Zhang, X. F., Shen, W. \&Gurunathan, S. Silver Nanoparticle-Mediated Cellular Responses in Various Cell Lines: An in Vitro Model. Int J.MolSci, 2016;17:16031615 .

21. Shahare, B. \&Yashpal, M. Toxic effects of repeated oral exposure of silver nanoparticles on small intestine mucosa of mice. ToxicolMech Methods. 2013; 23:161-167,

22. Bergin, I. L.. Effects of particle size and coating on toxicologic parameters, fecal elimination kinetics and tissue distribution of acutely ingested silver nanoparticles in a mouse model. Nanotoxicology. 2016; 10: 352-360.

23. Raies, A. B. \&Bajic, V. B. In silico toxicology: computational methods for the prediction of chemical toxicity. Wiley Interdiscip. Rev. Comput. Mol. Sc. 2016; 6:147-172.

24. Cheng LC, Jiang $X$ and Wang J. Nano-bioeffects: interaction of nanomaterials with cells. Nanoscale. 2013; 5:3547-3569. 
25. Studer, A.M., Limbach, L.K., Van Duc, L., Krumeich, F., Athanassiou, E.K., Gerber, L.C. Nanoparticle cytotoxicity depends on intracellular solubility: comparison of stabilized copper metal and degradable copper oxide nanoparticles. Toxicol Lett. 2012;197:169-174.

26. Liu, X.. Silver nanoparticles mediate differential responses in keratinocytes and fibroblasts during skin wound healing. Chem Med Chem. 2010; 5:468-475.

27. Boudreau M.D., Imam M. S., Paredes A.M., Bryant M. S., Cunningham C/ K., Felton R. P. Jones M.Y. Davis K. J. and Olson G. R. Toxicology Sciences. 2016;150: 131-160.

28. Kim YS, Kim JS, Cho HS, Rha DS, Kim JM, Park JD, Choi BS, Lim R, Chang HK, Chung YH, Kwon IH. Twentyeight-day oral toxicity, genotoxicity, and gender-related tissue distribution of silver nanoparticles in SpragueDawley rats. Inhalation Toxicology. 2008; 20:575-583.

29. Hussain SM, Hess KL, Gearhart JM, Geiss KT, Schlager $\mathrm{JJ}$ : In vitrotoxicity of nanoparticles in BRL 3A rat liver cells. Toxicol. In Vitro 2005, 19:975-983.

30. Furchner J.E., Richmond C.R., Drake G.A. Comparative metabolism of radionuclides in mammals-IV. Retention of silver- $110 \mathrm{~m}$ in the mouse, rat, monkey, and dog. Health Phys. 1968; 15: 505-514

31. Osborne O.J., Johnston B.D. Moger J. Balousha M, Lead JR, Kudoh T, and Tyler CR. Effects of particle size and coating on nanoscale $\mathrm{Ag}$ and $\mathrm{TiO}(2)$ exposure in zebrafish (Daniorerio) embryos Nanotoxicology. 2013;7:1315-1324.

32. East B.W., Boddy K., Williams E.D., Macintyre D and McLay, A.L. Silver retention, total body silver and tissue silver concentrations in argyria associated with exposure to an anti-smoking remedy containing silver acetate. Clin. Exp. Dermatol. 1980; 5:305-311.

33. Liu J., Sonshine D.A., Shervani S. and Hurt R.H. Controlled release of biologically active silver from nanosilver surfaces ACS. Nano. 2010; 4: 6903-6913.

34. Cheresh P., Kim S., Tulasiram S. and Kamp D. W. Oxidative stress and pulmonary fibrosis. Biochimica et Biophysica Acta. 2013; 1832: 1028-1040

35. Li H., Horke S., Forstermann U. Vascular oxidative stress, nitric oxide and atherosclerosis. Atherosclerosis. 2014; 237:208-219.
36. Freed J K., Gutterman. D D. Mitochondrial Reactive Oxygen Species and Vascular Function. Arterioscler. Thromb. Vasc. Biol. 2013; 33:673-675.

37. Cortese-Krott MM, Munchow M, Pirev E, Hessner F, Bozkurt A. Silver ions induce oxidative stress and intracellular zinc release in human skin fibroblasts. Free Radic.Biol Med. 2009; 47: 1570-1577.

38. Franco R., Sánchez-Olea R. and Reyes-Reyes E.M., Panayiotidis M.I.Environmental toxicity, oxidative stress and apoptosis: ménage à Trois. Mutat. Res. 2009; 674 : $3-22$

39. Dowsett M, Smith IE and Ebbs SR. Proliferation and apoptosis asmarkers of benefit in neoadjuvant endocrine therapy of breast cancer. Clin. Cancer Res. 2006; 12; 1024s-1030s.

40. Majno $G$ and Joris I. Apoptosis, oncosis, and necrosis: an overview of cell death. Am. J. Pathol.1995; 146:3-15.

41. Scholzen and Gerdes J. The Ki-67 protein: from the known and the unknown. J. Cell Phys. 2000; 182: 311-322.

42. Jang H. Park k. K. , Son E. J , ${ }^{3}$ Kim E. Kwak J. Y. , Moon H. J. , and Yoon Jung H. Hyalinizing trabecular tumor of the thyroid: diagnosis of a rare tumor using ultrasonography, cytology, and intraoperative frozen sections. Ultrasonography. 2016; 35: 131-139.

43. Leonardo E, Volante M and Barbareschi M. Cell membrane reactivity of MIB-1 antibody to Ki67 in human tumors: fact or artifact? Appl. Immunohistochem. Mol. Morphol. 2007; 15; 220-223.

44. Hirokawa M, Carney JA. Cell membrane and cytoplasmic staining for MIB-1 in hyalinizing trabecular adenoma of the thyroid gland. Am. J. Surg. Pathol. 2000; 24; 575-578.

45. Faratian D., Munro A, Twelves C., and Bartlett J. Membranous and cytoplasmic staining of $\mathrm{Ki67}$ is associated with HER2 and ER status in invasive breast carcinoma. Histopathology. 2009; 54:254-257.

46. Ciardiello F, and Tortora G. Review: Epidermal growth factor receptor (EGFR) as a target in cancertherapy: understanding the role of receptor expression andother molecular determinants that could influence the responseto anti-EGFR drugs. European Journal of Cancer.2003; 39 : 1348-1354. 